\title{
Flexural Characteristics of Sunlight-Aged Polyester Composites: Influence of Processing Variables
}

REFERENCE: Segovia López, F., Ferrer, C., Salvador, M. D., and Amigo, V., "Flexural Characteristics of Sunlight-Aged Polyester Composites: Influence of Processing Variables," Journal of Testing and Evaluation, JTEVA, Vol. 30, No. 1, Jan. 2002, pp. 20-26.

\begin{abstract}
This work presents the results of flexural tests carried out on samples aged for different periods of time in a UV-Visible light chamber. The processing variables studied were the type of reinforcing fabric, the resin type, and the cure conditions. The evolution of flexural characteristics with time exposure adjusts to a mathematical model that corresponds to a damped exponential curve. The aging degree varies between 16 and $41 \%$, depending on the preparation of the composites and the mechanical characteristics of the material. The aged material featured losses of its mechanical properties, and more on toughness than on strength properties. The kind of unsaturated $o$-phthalic polyester resin used showed no influence on the loss of mechanical properties. High cure temperatures decreased the loss of toughness to a higher degree than that observed for the loss of strength. The configuration of the reinforced fabrics used also influenced the mechanical properties: a mixed taffeta-multiaxial reinforced configuration leads to a high loss index on toughness properties and modulus of the composite.
\end{abstract}

KEYWORDS: polyester-matrix composites, glass fiber fabrics, flexural properties, sunlight degradation, manufacturing variables

Reinforced composites made of unsaturated polyester-glass fiber are being used increasingly in different industrial applications. Lightness, low cost, good mechanical strength, corrosion resistance, and relatively easy processing procedures are some of the interesting properties that lead these materials to be successfully applied in both the transportation and chemical industries. The state of heat degradation of polyester-based composites has been reviewed by Dudgeon [1]. Nevertheless, recent studies have been focused on the durability of these materials in organic and aqueous [2-15], alkaline [9,16,17], and acid media [9-11,17-19]. Effects of sunlight and high-energy radiation on nonreinforced polymers are well known [20-27], but similar information is scarce regarding composites. Some authors have reported the effects of sunlight on the surface and on the fiber-matrix interface [28,29]. Davis [24] claimed that both the kind of catalyst and the polyester resin used influenced the degree of aging, although no data have been published. Moreover, there are no concrete specifi-

Manuscript received 2/9/2001; accepted for publication 8/22/2001

${ }^{1}$ Composite Materials Laboratory's senior research and research engineers, respectively, Department of Mechanic and Materials Engineering, Polytechnic University of Valencia, Cno de Vera S/N 46022 Valencia, Spain. cations about the composite characteristics. The influence of processing variables on the aging behavior of the composite is also an interesting aspect that has not been studied extensively [30]. The present work correlates mechanical characteristics and the aging degree of different composites with the following processing parameters: curing cycle, reinforcement characteristics, and nature of the resin.

The literature in many cases reports raw experimental data without correlating them with any mathematical model that allows interpretation. The correlation of experimental data with a mathematical model would permit determining the evolution of mechanical characteristics of the composite during its life [31-33]. This approach will increase the possibility of predicting material failures and therefore assisting its maintenance. An important contribution of this work is the development of a mathematical model that correlates the mechanical characteristics of the material with the time of aging.

\section{Experimental and Sample Preparation}

\section{Materials}

As aforementioned, three different parameters were considered in the preparation of the composites: resin type, reinforcing fabric, and cure temperature. Two different $o$-phthalic polyester resins of extensive commercial application have been selected: (A) a BASF $\mathrm{P}^{\mathrm{TM}}$ of medium reactivity and (B) a BASF $\mathrm{P}^{\mathrm{TM}}$ of high reactivity. Mechanical characteristics of these resins are presented in Table 1. Methyl ethyl ketone peroxide, at $1.5 \% \mathrm{v} / \mathrm{v}$ in relation to the resin volume, was used as the catalyst and cobalt octanoate, at $0.15 \% \mathrm{v} / \mathrm{v}$, was used as the accelerator. Two different E-type fiberglass fabrics were used: waved taffeta with a specific weight of 300 $\mathrm{g} / \mathrm{m}^{2}$ and plain multiaxial 2D of $440 \mathrm{~g} / \mathrm{m}^{2}$. Fibers were arranged at 0 to $90^{\circ}$ in both cases. One-third of $\pm 45^{\circ}$ multiaxial 2D fabric of $440 \mathrm{~g} / \mathrm{m}^{2}$ was also used close to the 0 to $90^{\circ}$ taffeta fabric in order to simulate a mixed configuration composite. All composites were obtained by a hand layup method.

Two curing temperatures were used: room temperature (16 to $18^{\circ} \mathrm{C}$ ) and $40^{\circ} \mathrm{C}$ as a mild temperature. The first temperature is typical in low-cost production. The second one is more utilized for larger products that need better curing conditions at the lowest possible manufacturing cost, which is the case of the truck, railway, tank, and swimming pool industries. Demolding of the composites was performed after $24 \mathrm{~h}$. Nonirradiated samples were tested three days after being demolded and this was the time taken as the reference time. Characteristics and nomenclature of these samples are shown in Table 2. The range of the sample density 
TABLE 1-Mechanical characteristics of neat resins.

\begin{tabular}{lcc}
\hline \multicolumn{1}{c}{ Properties } & $\begin{array}{c}\text { Resin A } \\
\text { (P5) }\end{array}$ & $\begin{array}{c}\text { Resin B } \\
(\mathrm{P} 6)\end{array}$ \\
\hline Tensile Strength, $\mathrm{MPa}$ & 80 & 65 \\
Break Strain, \% & 2.0 & 2.0 \\
Flexural Strength, $\mathrm{MPa}$ & 110 & 115 \\
Flexural Modulus, $\mathrm{GPa}$ & 4.0 & 4.5 \\
Impact Toughness, $\mathrm{kJ} / \mathrm{m}^{2}$ & 14 & 20 \\
Heat Distortion Temperature, ${ }^{\circ} \mathrm{C}$ & 70 & 95 \\
\hline
\end{tabular}

TABLE 2-Laminates nomenclature code and configuration of composite laminates.

\begin{tabular}{llccl}
\hline Laminate & Configuration & Resin & $\begin{array}{c}\text { Cure } \\
\text { Temperature }\end{array}$ & $\begin{array}{c}\text { Reinforcing } \\
\text { Fabric }\end{array}$ \\
\hline AM & $\left(0-90^{\circ}\right)_{8}$ & A & $17^{\circ} \mathrm{C}$ & Multiaxial 2D \\
BM & $\left(0-90^{\circ}\right)_{8}$ & B & $17^{\circ} \mathrm{C}$ & Multiaxial 2D \\
AMC & $\left(0-90^{\circ}\right)_{8}$ & A & $40^{\circ} \mathrm{C}$ & Multiaxial 2D \\
BMC & $\left(0-90^{\circ}\right)_{8}$ & B & $40^{\circ} \mathrm{C}$ & Multiaxial 2D \\
AT & $\left(0-90^{\circ}\right)_{8}$ & A & $16^{\circ} \mathrm{C}$ & Taffeta \\
AX & $\left(0-90^{\circ} \%^{\circ} \pm 5^{\circ}\right)_{4}$ & A & $18^{\circ} \mathrm{C}$ & Taffeta + \\
& & & & Multiaxial 2D \\
\hline
\end{tabular}

was very narrow: 1.58 to $1.63 \mathrm{~g} / \mathrm{cm}^{3}$. The fiber volume content varied from 32.0 to $33.4 \%$ and the void content was between 2.5 and $8.9 \%$.

\section{Mechanical Testing}

Flexural tests were performed in accordance with ASTM D $790 \mathrm{M}-86$, by means of a universal testing machine, the INSTRON $^{\circledR} 4204$, and a three-point loading device. Five coupons were tested for each condition and their dimensions were: width = $25 \mathrm{~mm}$, span length $=120 \mathrm{~mm}$, and total length $=150 \mathrm{~mm}$. Thickness varied from $3 \mathrm{~mm}$ in taffeta laminates to $3.9 \mathrm{~mm}$ in mixed laminates, and $4.5 \mathrm{~mm}$ in the whole multiaxial 2D configuration. The cross head speed was $5 \mathrm{~mm} / \mathrm{min}$.

Data obtained in this test allowed the calculation of mechanical characteristics such as: flexural elastic modulus $E$; flexural strength $F S$, which is the maximum load a sample supports; relative deflection $\% D$, which is the maximum load applied; and the break specific energy $B S E$, which is the area under the stress-strain curve up to the sample break.

$E$ is calculated by drawing a tangent at the steepest initialstraight-line portion of the load-deflection curve and applying its slope to the following equation:

$$
E=\frac{L^{3} m}{4 w d^{3}}
$$

where $L$ is the support span in mm, $w$ is the width of the sample in $\mathrm{mm}, d$ is the depth of sample in $\mathrm{mm}$, and $m$ the slope of the tangent at the initial straight-line portion of load-deflection curve in N/mm of deflection. Equation 2 is used to calculate $F S$ :

$$
F S=\frac{3 F L}{2 w d^{2}}
$$

where $L, w$, and $d$ are the same variables as in Eq 1 and $F$ is the load in $N . \% D$ is defined as the relative deflection when the maximum strain in the outer fibers occurs at midspan. It can be calculated from $\mathrm{Eq}$ 3:

$$
\% D=\frac{600 D d}{L^{2}}
$$

where both $d$ and $L$ are the same as in Eqs 1 and 2, and $D$ is the maximum deflection on the center of the sample, in $\mathrm{mm}$.

\section{Exposure Testing}

Light from lamps adjusted to emit the ultraviolet and visible emission (UVV) of the solar spectrum (from 300 to $2000 \mathrm{~nm}$ ) was used as the aging agent. Samples were placed in a closed chamber of $90 \mathrm{~cm}$ diameter three days after being demolded. This chamber was maintained with three lamps each rated at $300 \mathrm{~W}$. Each of the lamps was positioned in such a way that the samples were perpendicular to the lamps. The final distance between the samples and the lamps was $50 \mathrm{~cm}$. The surface of each sample containing first 0 to $90^{\circ}$-orientation ply was selected to receive the maximum dose of UVV radiation. For the flexural tests, the exposed surface was placed directly upon the supports of the flexural devices. The loading nose acted against the unexposed coupon surface.

The coupons at the bottom of the chamber received an irradiation dose equivalent to $1700 \mathrm{~W} / \mathrm{m}^{2}$. The tests were carried out in the city of Valencia, which is located in the center of the East Spanish Mediterranean coast, $39^{\circ} 30^{\prime} \mathrm{N}$ and $0^{\circ} 25^{\prime} \mathrm{W}$. The Eastern Spanish Meteorology and Forecast Weather Service reports that this region receives about $310 \mathrm{~W} / \mathrm{m}^{2}$ in a standard day of $10 \mathrm{~h}$ of average exposure. One year consists of 365 of these standard days. Comparing this information with the data of the chamber, it was estimated that $1000 \mathrm{~h}$ of testing is equal to 1.64 years of real time exposure. Time measurements were $0,500,1000,1500$, and $7000 \mathrm{~h}$. A thermometer inside the chamber showed $50^{\circ} \mathrm{C}$. The heat from the lamps and the steady environment caused the increase in temperature.

\section{Results and Discussion}

\section{Degradation Model}

Tables 3 and 4 show the mechanical characteristics obtained from the flexural tests. Elastic modulus and flexural strength are

TABLE 3-Flexural properties of BM, AMC, and BMC composite laminates.

\begin{tabular}{lrcccc}
\hline Laminate & $\begin{array}{c}\text { Time, } \\
\mathrm{h}\end{array}$ & $\% D$ & $E, \mathrm{GPa}$ & $F S, \mathrm{MPa}$ & $\begin{array}{c}B S E, \\
\mathrm{~J} / \mathrm{cm}^{3}\end{array}$ \\
\hline \multirow{2}{*}{$\mathrm{BM}$} & 0 & $3.9 \pm 0.1$ & $12.7 \pm 0.2$ & $376 \pm 8$ & $15.7 \pm 0.9$ \\
& 500 & $3.7 \pm 0.1$ & $12.3 \pm 0.3$ & $357 \pm 7$ & $13.9 \pm 0.7$ \\
& 1000 & $3.5 \pm 0.1$ & $11.8 \pm 0.2$ & $348 \pm 4$ & $12.9 \pm 0.6$ \\
& 1500 & $3.3 \pm 0.2$ & $11.4 \pm 0.4$ & $336 \pm 8$ & $11.5 \pm 1.0$ \\
& 7000 & $3.0 \pm 0.1$ & $10.4 \pm 0.4$ & $304 \pm 5$ & $9.3 \pm 0.6$ \\
\hline \multirow{2}{*}{$\mathrm{AMC}$} & 0 & $4.1 \pm 0.1$ & $13.3 \pm 0.3$ & $389 \pm 10$ & $17.6 \pm 1.1$ \\
& 500 & $3.8 \pm 0.1$ & $12.7 \pm 0.3$ & $375 \pm 8$ & $15.5 \pm 0.9$ \\
& 1000 & $3.7 \pm 0.1$ & $12.2 \pm 0.4$ & $353 \pm 7$ & $14.0 \pm 0.7$ \\
& 1500 & $3.6 \pm 0.1$ & $11.9 \pm 0.3$ & $343 \pm 7$ & $13.3 \pm 0.5$ \\
& 7000 & $3.3 \pm 0.1$ & $11.0 \pm 0.4$ & $316 \pm 8$ & $10.9 \pm 0.9$ \\
\hline \multirow{2}{*}{ BMC } & 0 & $4.2 \pm 0.1$ & $12.9 \pm 0.4$ & $395 \pm 7$ & $17.9 \pm 1.4$ \\
& 500 & $4.0 \pm 0.1$ & $12.5 \pm 0.2$ & $369 \pm 6$ & $15.5 \pm 0.5$ \\
& 1000 & $3.8 \pm 0.1$ & $12.1 \pm 0.3$ & $353 \pm 7$ & $14.0 \pm 0.6$ \\
& 1500 & $3.6 \pm 0.2$ & $11.6 \pm 0.1$ & $341 \pm 7$ & $12.8 \pm 0.7$ \\
& 7000 & $3.4 \pm 0.2$ & $10.7 \pm 0.2$ & $314 \pm 6$ & $11.3 \pm 0.5$ \\
\hline & & & & &
\end{tabular}


considered as strength properties. Strain and break specific energy are reported as toughness properties. In this work, it was observed that all mechanical characteristics measured diminished with the time of exposure. Therefore, the accelerated exposure to simulated solar spectrum sources aged the unsaturated polyester glass fiber composites.

Data about the behavior of toughness and strength properties can be fitted into a mathematical model. The latter can be used to predict the behavior and the material's condition while in service. In Fig. 1, the flexural elastic modulus $E$ obtained for the different materials is plotted versus the time of sunlight exposure. It is observed that the damped exponential evolution of the curve can be fitted to the model represented in Eq 4:

$$
Y=A+B e^{-k t}
$$

where $Y$ represents the analyzed characteristics. In the example shown in Fig. 1, $Y$ corresponds to the elastic modulus, $A$ is the asymptotic value for long exposure times, $B$ is the difference between $Y$ value at time 0 and $A, k$ is the damping constant, and $t$ is the time of exposure, in $h$, in the aging chamber. All mechanical properties measured during the flexural test seem to follow this model. The correlation coefficients obtained for this model are presented in Tables 5 and 6 . Values of $R^{2}$, the coefficient of variation,

TABLE 4-Flexural properties of AM, AT, and AX composite laminates.

\begin{tabular}{crcccr}
\hline Laminate & $\begin{array}{c}\text { Time, } \\
\mathrm{h}\end{array}$ & $\% D$ & $E, \mathrm{GPa}$ & $F S, \mathrm{MPa}$ & \multicolumn{1}{c}{$\begin{array}{c}B S E, \\
\mathrm{~J} / \mathrm{cm}^{3}\end{array}$} \\
\hline \multirow{2}{*}{$\mathrm{AM}$} & 0 & $3.9 \pm 0.2$ & $12.5 \pm 0.2$ & $369 \pm 10$ & $15.8 \pm 1.0$ \\
& 500 & $3.8 \pm 0.1$ & $11.9 \pm 0.3$ & $356 \pm 6$ & $14.0 \pm 0.9$ \\
& 1000 & $3.6 \pm 0.1$ & $11.4 \pm 0.3$ & $338 \pm 10$ & $12.6 \pm 0.9$ \\
& 1500 & $3.5 \pm 0.1$ & $11.2 \pm 0.2$ & $333 \pm 4$ & $12.1 \pm 0.5$ \\
& 7000 & $3.1 \pm 0.2$ & $10.1 \pm 0.3$ & $300 \pm 9$ & $9.8 \pm 0.7$ \\
\hline $\mathrm{AT}$ & 0 & $3.2 \pm 0.2$ & $14.6 \pm 0.4$ & $317 \pm 9$ & $11.3 \pm 1.0$ \\
& 500 & $2.9 \pm 0.2$ & $14.2 \pm 0.3$ & $306 \pm 7$ & $10.2 \pm 0.6$ \\
& 1000 & $2.8 \pm 0.1$ & $13.4 \pm 0.2$ & $295 \pm 4$ & $9.1 \pm 0.6$ \\
& 1500 & $2.7 \pm 0.1$ & $13.0 \pm 0.2$ & $285 \pm 3$ & $8.3 \pm 0.5$ \\
& 7000 & $2.5 \pm 0.2$ & $11.7 \pm 0.4$ & $257 \pm 5$ & $6.7 \pm 0.7$ \\
\hline \multirow{2}{*}{$\mathrm{AX}$} & 0 & $3.8 \pm 0.1$ & $10.7 \pm 0.9$ & $266 \pm 16$ & $11.1 \pm 1.3$ \\
& 500 & $3.6 \pm 0.1$ & $9.8 \pm 0.6$ & $242 \pm 10$ & $9.4 \pm 0.5$ \\
& 1000 & $3.4 \pm 0.2$ & $9.0 \pm 0.5$ & $228 \pm 10$ & $8.4 \pm 0.9$ \\
& 1500 & $3.2 \pm 0.2$ & $8.7 \pm 0.3$ & $223 \pm 6$ & $7.5 \pm 0.6$ \\
& 7000 & $2.9 \pm 0.1$ & $7.6 \pm 0.4$ & $203 \pm 9$ & $6.1 \pm 0.8$ \\
\hline
\end{tabular}

denote a high degree of correlation between experimental values and those predicted by the model.

Degradation takes place in the resin, whereas the fiberglass remains unaltered. Degradation will occur mainly in the near-surface layers rather than in the deep ones. Nevertheless, the radiation, though attenuated, will also enter the inner parts of the material be-

TABLE 5-Fitting coefficients of degradation model for multiaxial 2D composites.

\begin{tabular}{lclccc}
\hline \multirow{2}{*}{ Laminate } & Coefficients & $\% D$ & $\begin{array}{c}E, \\
\mathrm{GPa}\end{array}$ & $\begin{array}{c}F S, \\
\mathrm{MPa}\end{array}$ & $\begin{array}{c}B S E, \\
\mathrm{~J} / \mathrm{cm}^{3}\end{array}$ \\
\hline \multirow{2}{*}{$\mathrm{AM}$} & $A$ & 3.1 & 10.1 & 300 & 9.3 \\
& $B$ & 0.8 & 2.2 & 65 & 5.0 \\
& $k, 10^{-4} \mathrm{~h}^{-1}$ & 4 & 4 & 4 & 4 \\
& $R^{2}$ & 0.99 & 0.99 & 0.99 & 0.99 \\
\hline \multirow{2}{*}{$\mathrm{BM}$} & $A$ & 3.0 & 10.4 & 304 & 9.2 \\
& $B$ & 0.8 & 2.2 & 68 & 5.6 \\
& $k, 10^{-4} \mathrm{~h}^{-1}$ & 5 & 4 & 4 & 5 \\
& $R^{2}$ & 0.99 & 0.99 & 0.99 & 0.99 \\
\hline \multirow{2}{*}{$\mathrm{AMC}$} & $A$ & 3.3 & 11.0 & 316 & 10.9 \\
& $B$ & 0.7 & 2.1 & 65 & 5.5 \\
& $k, 10^{-4} \mathrm{~h}^{-1}$ & 4 & 5 & 5 & 5 \\
& $R^{2}$ & 0.99 & 0.99 & 0.99 & 0.99 \\
\hline \multirow{2}{*}{$\mathrm{BMC}$} & $A$ & 3.4 & 10.7 & 314 & 11.3 \\
& $B$ & 0.7 & 2.1 & 67 & 4.9 \\
& $k, 10^{-4} \mathrm{~h}^{-1}$ & 5 & 5 & 5 & 5 \\
& $R^{2}$ & 0.98 & 0.99 & 0.99 & 0.97 \\
\hline
\end{tabular}

TABLE 6-Fitting coefficients of degradation model for taffeta and mixed composites.

\begin{tabular}{cccccl}
\hline \multirow{2}{*}{ Laminate } & Coefficients & $\% D$ & $\begin{array}{c}E, \\
\mathrm{GPa}\end{array}$ & $\begin{array}{c}F S, \\
\mathrm{MPa}\end{array}$ & $\begin{array}{l}B S E, \\
\mathrm{~J} / \mathrm{cm}^{3}\end{array}$ \\
\hline \multirow{2}{*}{$\mathrm{AT}$} & $A$ & 2.5 & 11.7 & 257 & 6.7 \\
& $B$ & 0.5 & 2.9 & 58 & 4.2 \\
& $k, 10^{-4} \mathrm{~h}^{-1}$ & 5 & 5 & 4 & 5 \\
& $R^{2}$ & 0.98 & 0.99 & 0.99 & 0.99 \\
\hline \multirow{2}{*}{$\mathrm{AX}$} & $A$ & 2.9 & 7.6 & 203 & 5.9 \\
& $B$ & 0.8 & 2.6 & 48 & 4.1 \\
& $k, 10^{-4} \mathrm{~h}^{-1}$ & 5 & 5 & 5 & 5 \\
& $R^{2}$ & 0.99 & 0.99 & 0.98 & 0.99 \\
\hline
\end{tabular}

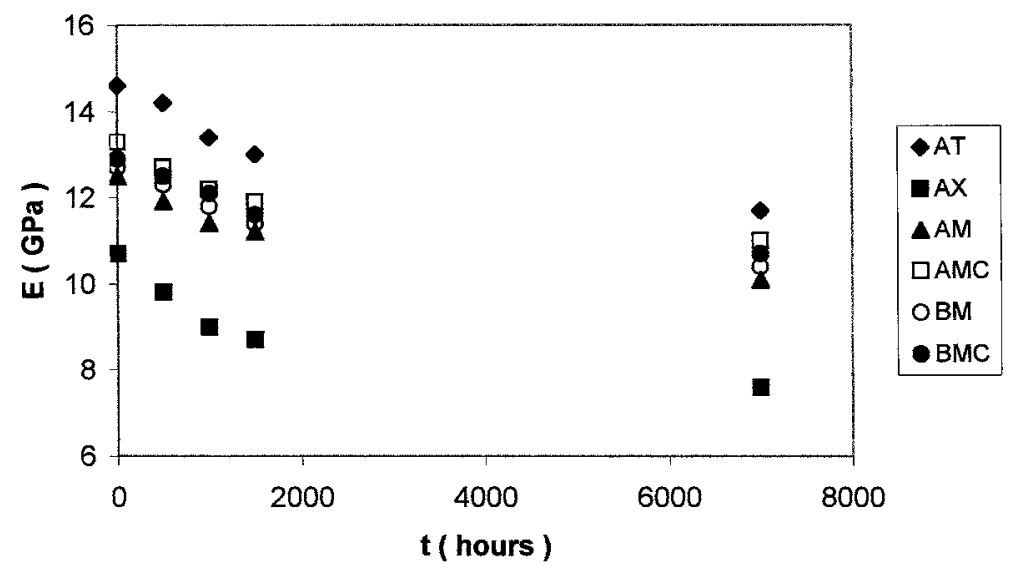

FIG. 1-Elastic modulus evolution versus exposure time for different composites. 
cause both the resin and the fibers are translucent. It is known that light attenuation in a material follows an exponential law. Accordingly, the accumulated damage after sunlight exposure implies variations in the strength and toughness of these materials that can be adjusted to the decreasing exponential model already shown.

Losses in mechanical properties by UVV light irradiation can be attributed to a photo-oxidation mechanism. Several authors have described the different aspects of these mechanisms and the correlation with mechanical strength and toughness in thermoplastics and thermosetting polymers [34-40]. The degradation mechanism in a polymer by the action of UV rays was established 50 years ago. Bolland [41] demonstrated that molecular photo-oxidation is initiated by the formation of active free radicals and oxygen fixation. Carbonyl groups initially are produced in this way, leading to the cleavage of the molecule afterwards. In longer chain molecules, like unsaturated o-phthalic polyesters, irradiation of UVV produces vinyl, aldehyde, or carbonyl groups [41].

Styrene is the crosslinking agent in unsaturated polyesters. Several authors have suggested that some unreacted resin and catalyst that did not take part in the polymerization reaction are still present [9-11,42]. It is well known that three types of reactions are inherent in unsatured polyesters: curing polymerization of polyester vinyl groups, polyester and styrene $\mathrm{C}=\mathrm{C}$ bond polymerization, and styrene homopolymerization [42-46]. In thermosetting resins, chemical reactions between these reactive groups practically stop when vitrification occurs. After vitrification takes place, chemical reactions can occur only by physical diffusion in the resin and chemical polymerization reactions are highly constrained $[47,48]$. Therefore, photo-oxidation of the molecular fraction containing the polystyrene occurs by one of the following mechanisms: molecular rupture and posterior oxidation [49], yielding peroxide reactant radicals that later produce vinyl and carbonyl groups and water [50], or the formation of alkyl ketone, quaternary alcohol, and oxygen [51]. Another possible mechanism is the crosslinking of polystyrene segments together with molecular rupture, forming alkene, benzylketone, and vinyl groups [52]. Scott [28] reports a photo-oxidation phenomenon in unreacted vinyl groups of the polyester resin, as well as in unreacted free styrene. As a consequence of this photochemical reaction, the polymer features a characteristic yellowish color that also appears in our samples. On the other hand, the presence of trace amounts of free peroxide catalyst that were not removed during polyester polymerization is another possible cause of photo-oxidation [50].

Wiles [53,54] suggested a mixed mechanism of thermal and photolytic oxidation in polymers containing carbonyl groups in the form of acid, ester, aldehyde, ketone, amide, or peroxide. Glass fiber reinforced polyester composites continuously exposed to a temperature of $50^{\circ} \mathrm{C}$ do not lose their mechanical characteristics in the absence of solar radiation, as shown in a number of references [9-11,30]. The prevalent mechanism during composite irradiation is photoluminic, while thermal aging would produce higher losses due to fiber-matrix interface degradation $[12,13,55]$.

\section{Influence of the Resin}

Determination of the mechanical characteristics loss index $(\Delta \%)$ is obtained from Eq 5, in which $A+B$ represents the initial value, and $B$ the difference between the initial value and the asymptotic one predicted by the aging model.

$$
\Delta \%=\frac{B}{A+B} 100
$$

TABLE 7-Flexural characteristics loss index $\Delta \%$ for multiaxial $2 D$ composites.

\begin{tabular}{lcccc}
\hline Composite & $E$ & $F S$ & $\% D$ & $B S E$ \\
\hline AM & 18 & 18 & 21 & 35 \\
BM & 17 & 18 & 21 & 38 \\
AMC & 16 & 17 & 16 & 34 \\
BMC & 16 & 18 & 16 & 30 \\
\hline
\end{tabular}

The loss indexes of the different materials studied are presented in Table 7. The resin influence is determined by comparison of AM and BM laminates. Losses of $E$ and $F S$ are similar for each laminate and vary between $16 \%$ and $18 \%$. In the same way, both AM and $\mathrm{BM}$ laminates show reductions of $21 \%$ in $\% D$ in relation with the initial state. BSE losses do not depend on the type of resin used, but are quantitatively high, $35 \%$ to $38 \%$, as a consequence of the accumulated deterioration of $E, F S$, and $\% D$. Higher $\Delta \%$ indexes were found for toughness properties ( $\% D$ and $B S E$ ) than for strength ones. UVV radiation degrades the thermosetting matrix and reduces the crosslink density. It also produces negative effects in the stability of the resin and the resin-fiber interface such as stress concentration, brittleness, and a tendency for matrix-fiber debonding [56-58].

Losses in the $40^{\circ} \mathrm{C}$-cured laminates $\mathrm{AMC}$ and $\mathrm{BMC}$ are shown in Table 7. The values of strength properties are very close, between $16 \%$ and $18 \%$. Both laminates present a loss of $16 \%$ in $\% D$ characteristic, but the $\Delta \%$ index of $B S E$ is higher than that of the strength ones: $34 \%$ to AMC and $30 \%$ to BMC. Though BMC laminate presents a loss index value of $B S E$ slightly lower than the $\mathrm{AMC}$, when the loss indexes of toughness properties of the four laminates are compared, the results show no evidence of the influence of the resin used. The same can be observed when the strength properties $\Delta \%$ of $\mathrm{AM}, \mathrm{BM}, \mathrm{AMC}$, and BMC laminates are compared. This indicates that the difference in reactivity of both resins does not produce dissimilar degrees of polymerization. Therefore, its influence is not significant for the same family of unsaturated $o$-phthalic polyesters.

\section{Influence of the Cure Temperature}

Table 7 shows the results obtained for two composites, AM and AMC, cured at room temperature and at $40^{\circ} \mathrm{C}$, respectively. It can be observed that losses in modulus and strength in AMC laminates (16 and 17\%), are slightly lower than those observed for AM (18\%). Losses of BSE are higher than those of the strength properties. Nevertheless, the values are similar for both laminates (34 and $35 \%)$. The composite cured at $40^{\circ} \mathrm{C}$ featured a better $\Delta \%$ index for the $\% D$ characteristic than did the composite cured at room temperature (16\% versus $21 \%$ ).

$\mathrm{BM}$ and $\mathrm{BMC}$ are laminates cured at room temperature and at $40^{\circ} \mathrm{C}$, respectively. Results observed in these two materials confirm the importance of the curing temperature on the mechanical characteristics loss index. In fact, $F S$ and $E$ do not show differential degradability, but toughness properties do. While $\% D$ and $B S E$ loss indexes are respectively 21 and $38 \%$ for BM, these values decrease to 16 and $30 \%$ for BMC laminate. Therefore, the use of a higher cure temperature seems to diminish losses of mechanical properties. Moreover, it seems to be that the toughness properties are more influenced by the temperature of cure than are the strength properties. As the cure temperature rises, a higher degree of polymerization of the resin and crosslink density are also achieved 


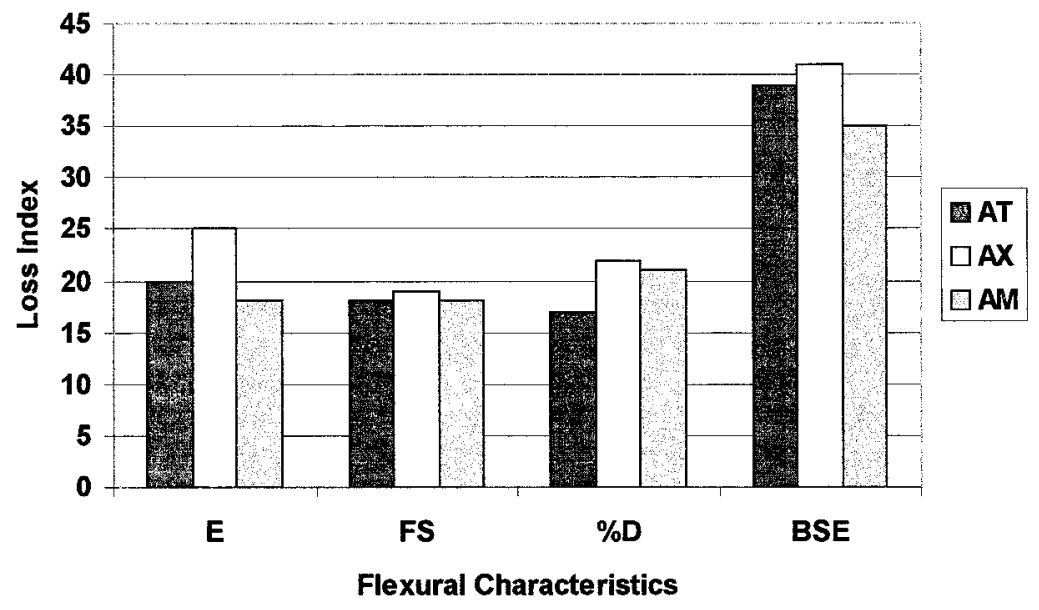

FIG. 2-Mechanical characteristic loss index $\Delta \%$ for laminates with different reinforcing configurations.

[9,59]. High temperatures lead to an increase of the segmental mobility of the resin, as well as to polymerization $[45,60,61]$, which result in better adherence of the matrix-fiber $[9,55,56]$.

\section{Influence of the Reinforcement Fabric}

Three different fiber-reinforcing fabrics used to elaborate composites are compared: taffeta AT, 2D multiaxial AM, and a mixed taffeta-multiaxial AX. Data in Fig. 2 show that the losses of FS coincide for the three laminates, $18 \%$ to $19 \%$. Only the laminate of AX mixed configuration exhibits some high losses (25\% for E). Similar losses are observed for $\% D$, from 17 to $22 \%$. The loss index of AX laminate presents a value of $22 \%$, which is higher than the index of taffeta composite $(17 \%)$, but close to the AM one (21\%). BSE results featured larger losses and it seems that this characteristic is more sensitive to degradation effects. The $\Delta \%$ index ranges from 35 to $41 \%$. These values are, again, high for the AX laminate, although AT features an only slightly lower value (39\%). This means that the configuration of the reinforcing fabric has some influence, although it is not pronounced, on the losses of $B S E$ characteristics. In both $\% D$ and $B S E$ toughness characteristics, AX laminate exhibits higher values of losses than does AM or AT. This fact is also observed for the modulus $E$.

The sensitive response of $\pm 45^{\circ}$ fibers in the flexural tests and an excessive damage at the interface of the matrix- $\pm 45^{\circ}$ fibers could justify the high loss index. Another reason could be the lack of coupling between stresses and strain in laminates configured with different kinds of fiber orientations, as has been described by Hull [62]. Although taffeta samples are thinner, the compact arrangement of fibers, such as the waved one in the taffeta laminate, seems to be a decisive factor that does not worsen their strength and toughness properties loss index. The responses of AM samples towards aging on $E$ and $B S E$ characteristics are better than those for AX samples. This could be justified by the larger thickness of the former, which yields lesser damage.

\section{Conclusions}

The exposure of glass fiber polyester composites to sunlight produces a significant reduction in their flexural characteristics. The degradation pattern of the mechanical characteristics fits a damped decreasing exponential curve. The mathematical model used gives a good correlation coefficient, where the degradation would be exclusively due to a photo-oxidative mechanism.
Flexural modulus and strength, taken as strength properties, reach relevant losses of 18 to $25 \%$. On the other hand, break strain and break specific energy, which were considered as toughness properties, showed to be more sensitive to degradation, with losses ranging from 16 to $41 \%$. This behavior is due to the induced brittleness in the resin and fiber-matrix interface.

The three processing variables have different influences on the comparative degradability of the composites. The influence of the resin is negligible when they belong to the same family of unsaturated polyesters (i.e., the $o$-phthalic group).

Low cure temperatures increase losses. This effect is more remarkable in toughness properties than in strength ones. Higher crosslinking density and improved adhesion of the resin to the glass fiber appear as some effects of high cure temperatures.

Use of reinforcing fabric combinations such as taffeta 0 to $90^{\circ}$ multiaxial $\pm 45^{\circ}$ in the mixed composite increases the losses of mechanical characteristics such as $E, \% D$, and $B S E$. Both taffeta and multiaxial 2D, used in pure configurations, present some resistance towards degradation.

\section{References}

[1] Dudgeon, C. D., Ed., Composites: Engineered Materials Handbook, Vol. 1., ASM International, Metals Park, OH, 1988, pp. 90-96.

[2] Springer G. S., Sanders, B. A., and Tung R. W., "Environmental Effects on Glass Fiber Reinforced Polyester and Vinylester Composites," Journal of Composite Materials, Vol. 14, 1980, pp. 213-233.

[3] Castaing, P., Lemoine, L., and Tsouvalis, N., "Experimental Study of the Variation in Mechanical Characteristics of Orthotropic Laminates Immersed in Water," 9th ICCM Proceedings, Madrid, Vol. 5, 1993, pp. 577-584.

[4] Karama, M., Touratier, M., and Pegorarol, P., "Test of Accelerated Aging Composite Materials in Shipbuilding," 9th ICCM Proceedings, Madrid, Vol. 5, 1993, pp. 585-592.

[5] Davis, P., Choqueuse, D., Mazéas, F., and Le Bras, J., "Composites Underwater," DURACOSYS 97 Proceedings, Blackburg, VA, 1997, pp. 1.9-1.12.

[6] Choqueuse, D., Davis, P., Mazéas, F., and Baizeau, R., "Aging of Composites in Water," ASTM STP 1302, ASTM International, West Conshohocken, PA, 1997, pp. 73-96.

[7] Bogner, B. R. "Glass-fiber Reinforced Underground Storage Tanks for Europe,” Composites, Vol. 3, 1991, pp. 69-73. 
[8] Florio, J., Rose, V. C., and Rockett, T. J., "Effects of Selected Manufacturing Procedures on Water Resistance of Marine Laminates," 42nd Annual Conference, SPI Reinforced Plastics/Composites Institute, 1988, Paper 15-F.

[9] Siddaramaiah, Suresh, S. V., Atul, V. B., Srinivas, D., and Girish, S., "Effect of Aggressive Environment on Composites Properties," Journal of Applied Polymer Science, Vol. 73, 1999, pp. 795-799.

[10] Valea, A., González, M. L., and Mondragón, I., "Vinyl Ester and Unsatured Polyester Resins in Contact with Different Chemicals: Dynamic Mechanical Behavior," Journal of Applied Polymer Science, Vol. 71, 1999, pp. 21-28.

[11] Valea, A., Martínez, I., González, M. L., Eceiza, A., and Mondragón, I., "Influence of Cure Schedule on the Dynamic Mechanical Behavior of Vinyl Ester Resin Containing Glass Fibers," Journal of Applied Polymer Science, Vol. 70, 1998, pp. 2595-2602.

[12] Liao, K., Schultheisz, C. R., and Hunston, D. L., "Long-term Environmental Fatigue of Pultruded Glass-Fiber Reinforced Composites under Flexural Loading," International Journal of Fatigue, Vol. 21, 1999, pp. 485-495.

[13] Liao, K., Schultheisz, C. R., and Hunston, D. L., "Effects of Environmental Aging on the Properties of Pultruded GFRP," Composites Part B: Engineering, Vol. 30, 1999, pp. 485-493.

[14] Bradley, W., Chiou, P. B., and Grant, T., "The Effect of Seawater on Polymeric Composites Materials," In: Wang, Fitting, Eds. Composite Materials for Offshore Operations. Proceedings of the First International Workshop, NIST Special Publication 887, 1995, pp. 193-202.

[15] Verghese, K. N., Hayes, M. D., Garcia, K., Carrier, C., Wood, J., Riffle, J. R., et al., "Influence of Matrix Chemistry on Short Term, Hydrothermal Aging of Vinyl Ester Matrix and Composites Under Both Isothermal and Thermal Spiking Conditions," Journal of Composite Materials, Vol. 33, 1999, pp. 1918-1938.

[16] Somiya, S. and Morishita, T., "Study on the Degradation Phenomena of SMC in Alkaline Conditions," 9th ICCM Proceeding, Madrid 1993, Vol. 5, pp. 554-561.

[17] McInally, A., The Properties and Applications of a New Epoxy-Vinyl-Ester Resin for Corrosion Resistant Applications, Ph.D. thesis, University of Witwatersrand, Johannesburg, RSA, 1995.

[18] Caddock, B. D., Evensand, K. E., and Hull, D., Journal of Materials Science, Vol. 22, 1987, pp. 3368.

[19] Fujii, Y., Maekawa, Z., Hamada, H., Kubota, T., Murakami, A., and Yoshiki, T., "Evaluation of Initial Damage and Stress Corrosion of GFRP," 9th ICCM Proceedings, Madrid 1993, Vol. 5, pp. 562-568.

[20] Dole, M., The Radiation Chemistry of Macromolecules, Vol. 1, Academic Press, San Diego, CA, 1972.

[21] Morgan, J. T. and Stapleton, G. B., Gas Evolution from Plastic Materials by High Energy Radiation, Rutherford Laboratory Internal Report, RL 74-021, 1974.

[22] Evans, D. and Morgan J. T., "A Review of the Effects of Ionizing Radiation on Plastic Materials at Low Temperatures," Advanced Cryogenic Engineering 28, Plenum Publishing Corporation, New York, NY, 1982.

[23] Chang, C. K. and Camaratos, E., "Theoretical Studies of Radiation Effects in Composite Materials for Space Use," NASA CR 3618, Washington, D.C., 1982.

[24] Davis, A. and Sims, D., Weathering of Polymers, Elsevier Applied Science Publishers, Essex, 1986.
[25] Simon, N. J., A Review of Irradiation Effects on Organic-Matrix Insulation, US Department of Commerce, National Institute of Standards and Technology, NISTIR 3999, Boulder, CO, 1993.

[26] Evans, D. and Crook, M. A., "Irradiation of Plastics: Damage and Gas Evolution," Metal Research Society Bulletin, Vol. 22, No. 4, 1997, pp. 36-40.

[27] Evans, D., Reed, R. P., and Hazelton, C. S., "Fundamental Aspects of Irradiation of Plastic Materials at Low Temperatures," Cryogenics, Vol. 35, 1995, pp. 755-757.

[28] Scott, K. A. and Paul, K. T., Composites, Vol. 5, 1974, p. 201.

[29] Sholtz, D., Kunst., Vol. 68, 1978, p. 556.

[30] Segovia, F., Ferrer, C., Salvador, M. D., and Amigó, V., "Influence of Processing Variables on Mechanical Characteristics of Sunlight Aged Polyester-Glass Fiber Composites," Polymer Degradation and Stability, Vol. 71, No. 1, 2001, pp. 179-184.

[31] Boukhili, R., Bojji, C., and Gauvin, R., “A Feasibility Study on the Impact Fatigue Behavior of Composites," Final report prepared for National Defense Project CDT P1663, 1996.

[32] Boukhili, R., Bojji, C., and Gauvin, R., "Fatigue Mechanisms under Low Energy Repeated Impact of Composite Laminates," Journal of Reinforced Plastics \& Composites, Vol. 13, No. 10, 1994, pp. 856-870.

[33] Boukhili, R., Champoux, L., and Martin, S., "Effect of Water Absorption on the Low Energy Repeated Impact of Carbon/Epoxy Laminates," Durability Analysis of Composite Systems, Balkema Editors, Rotterdam, 1996, pp. 259-264.

[34] Vasely, R. and Kalenda, M., Kunst., Vol. 59, 1969, p. 107.

[35] Cotter, J. L. and Hockney, M. G., "The Weathering of Plastics and Rubbers," PRI Symposium, June 1976.

[36] Lind, R., Kunst., 1979, p. 397.

[37] Delprat, P. and Gardette J. L., Polymer, Vol. 34, No. 5, 1993 , pp. 903-937.

[38] Musto, P., Karasaz, W., and MacKnight, J., Polymer, Vol. 34, No. 14, 1993, pp. 2934-2945.

[39] Chua, S. M. and Henderson, P. J., Material Science Letters, Vol. 10, 1991, pp. 1379-1380.

[40] Carrasco, F., Arnau, J., and Pages, P., Composites, Vol. 2, 1993, pp. 46-52.

[41] Bolland, J. L., Quarterly Review Chemical Society, Vol. 1, 1949, p. 1.

[42] Liu, S. B., Liu, J. L., and Yu, T. L., Journal of Applied Polymer Science, Vol. 53, 1985, pp. 1165-1177.

[43] Yang, Y. S. and Lee, L. J., Polymer, Vol. 29, 1988, p. 1793.

[44] Jacobs, P. M. and Jones, F. R., Polymer, Vol. 33, 1992, p. 1418.

[45] Huang, Y. J. and Chen, C. J., Journal of Applied Polymer Science, Vol. 46, 1992, p. 1573.

[46] Caba, K., Guerrero, P., Eceiza, A., and Mondragón, I., European Polymer Journal, Vol. 33, 1997, p. 19.

[47] Schiering, D. W., Katon, J. E., Drzal, L. T., and Gupta, V. B., Journal of Applied Polymer Science, Vol. 34, 1987, p. 2367.

[48] Min, B. G., Stachurski, H., and Hodgking, J. H., Polymer, Vol. 34, 1993, p. 4908

[49] Ghiggino, K. P., Wright, R., and Phillips, D., Journal of Applied Polymer Science, Vol. 16, 1978, p. 1499.

[50] Genskens, G., Baeyens-Volant, D., Delaumois, G., In-Vinh, Q., Piret, W., and David, C., European Polymer Journal, Vol. 14, 1978, p. 291.

[51] Pudov, V. S., Buchachenko, A. L., and Uspekhi, K., Russian Chemical Review, Vol. 39, 1970, p. 70. 
[52] Nabil, M. S. and Samir, A. L., "Polystyrene Photoxidative Degradation of Cover Signals Lamp of Automobiles," Journal of Applied Polymer Science, Vol. 55, 1992, pp. 47-54.

[53] Wiles, B. M. and Day, M., Journal of Applied Polymer Science, Vol. 1, 1972, p. 175.

[54] Wiles, B. M. and Day, M., Journal of Applied Polymer Science, Vol. 1, 1972, p. 191.

[55] Segovia, F., Salvador, M. D., Amigó, V., and Bloem, C., "Thermal Aging Effects on $\mathrm{G}_{I I C}$ Interlaminar Fracture Mode Response of 2D-Composites," Recent Developments in Durability Analysis of Composite Systems, 2000. In: Balkema, A. A., Ed. Rotterdam, Netherlands 2000, pp. 259-263.

[56] Takkar, J. R., Patel, R. D., Patel, R. G., and Patel, V. S., Journal of Applied Polymer Science, Vol. 37, 1989, p. 1442.

[57] Apicella, A., Migliaresi, C., Nicodemo, L., Nicolais, L., Iac- carino, L., and Roccotelli, S., "Water Sorption and Mechanical Properties of a GRC Resin," Composites, October 1982, pp. 406-410.

[58] Schutte, C. L., "Environmental Durability of GFC," Materials Science and Engineering, Vol. 13, No. 7, 1994, pp. 256-323.

[59] Jagadeesh, K. S. and Siddaramaiah, Polymer International, Vol. 33, 1994, pp. 367-372.

[60] Ghorbel, I. and Valentin, D., Polymer Composites, Vol. 14, 1993, p. 324.

[61] Cook, W. D., Simon, G. P., Burchill, P. J., Lau, M., and Fitch, T. J., Journal of Applied Polymer Science, Vol. 64, 1997, p. 769.

[62] Hull, D., Composite Materials (Spanish language version of the book). In: Reverté, Ed., Barcelona, 1987. 